\title{
Combined use of coils and Onyx for transcatheter closure of coronary artery fistulae
}

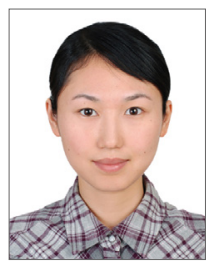

Pan Li ${ }^{1}$, MD; Xudong Xu ${ }^{1}$, MD; Zheng Zhang ${ }^{2}$, BSc; Feiyu Wang ${ }^{1}$, MD; Zhongkai Wang ${ }^{1}$, MD; Feng Chen ${ }^{1}$, MD; Bili Zhang ${ }^{1}$, MD; Yongwen Qin ${ }^{1}$; MD; Shaoping Chen ${ }^{1}$, MD;

Xianxian $\mathrm{Zhao}^{1 *}, \mathrm{MD}$

1. Department of Cardiology, Changhai Hospital, Second Military Medical University, Shanghai, China;

2. Department of Catheterization Laboratory, Changhai Hospital, Second Military Medical University, Shanghai, China

P. Li, X. Xu and Z. Zhang contributed equally to this work.

This paper also includes supplementary data published online at: http://www.pcronline.com/eurointervention/133rd_issue/353

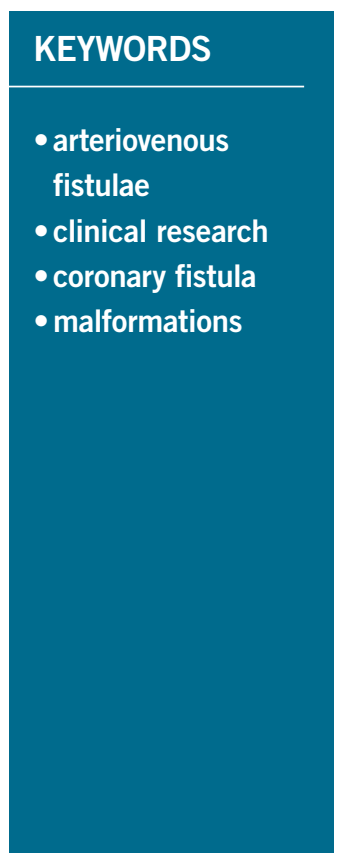

\begin{abstract}
Aims: The aim of this study was to evaluate the safety and efficacy of combined endovascular coiling and Onyx embolisation in patients with a coronary artery fistula (CAF).

Methods and results: Between September 2014 and September 2016, 26 patients with CAFs were enrolled in our study for attempted combined therapy using coils and Onyx. The mean age of patients was 64.0 09.5 years (range, $44-78$ years). CAFs were large in 10 and medium in 16 patients. The mean number of coils used was $3.1 \pm 1.2$ (range, two to six), and the average volume of Onyx was $0.4 \pm 0.1 \mathrm{ml}$ (range, 0.2$0.6 \mathrm{ml})$. Immediate post-embolisation angiography demonstrated that complete occlusion was achieved in 23 patients $(88.5 \%)$ and a small residual fistula was achieved in three patients (11.5\%). Follow-up imaging (median, 11.5 months; range, nine to 20 ) revealed stable occlusion of CAF in 21 cases (80.8\%), trivial recanalisation in four cases $(15.4 \%)$, and large recanalisation in only one case (3.8\%). Re-closure was performed in the patient with large recanalisation. During the follow-up period, no deaths, severe procedurerelated complications, or new symptoms occurred.
\end{abstract}

Conclusions: In selected patients with CAF, transcatheter embolisation in combined therapy using coils and Onyx appears to be a valid option, providing a high success rate and low rate of recanalisation.

\footnotetext{
*Corresponding author: Department of Cardiology, Changhai Hospital, Second Military Medical University, 168 Changhai Rd, Shanghai, 200433, China.E-mail: 13764924032@163.com
} 


\section{Abbreviations}

$\begin{array}{ll}\text { CAF } & \text { coronary artery fistula } \\ \text { DMSO } & \text { dimethyl sulfoxide } \\ \text { LAD } & \text { left anterior descending artery } \\ \text { PA } & \text { pulmonary artery } \\ \text { RCA } & \text { right coronary artery } \\ \text { TTE } & \text { transthoracic echocardiography }\end{array}$

\section{Introduction}

Despite its relatively rare occurrence, coronary artery fistula (CAF) remains the most common congenital coronary artery malformation $^{1}$. Small CAFs are usually an incidental finding in asymptomatic individuals but, when moderate to large, CAFs often produce symptoms and may cause complications including heart failure, myocardial ischaemia, infective endocarditis, or even heart rupture ${ }^{2,3}$. The American College of Cardiology/American Heart Association (2008) guidelines recommend intervening in all large fistulae, irrespective of whether symptoms are present, and in small to medium fistulae with symptoms ${ }^{4}$. In the past, surgery was the primary treatment for CAF, and this involved median sternotomy and cardiopulmonary bypass ${ }^{1,5}$. Less invasive techniques providing lower morbidity include various endovascular techniques such as the use of coils $^{2}$, vascular plugs ${ }^{6}$, covered stents ${ }^{7}$, and the AMPLATZER ${ }^{\text {TM }}$ Duct Occluder (St. Jude Medical, St. Paul, MN, USA) ${ }^{8}$. At present, detachable coils are the most commonly used materials for CAF, but these have limited applications for large or twisted fistulae due to the high rate of recanalisation and expense.

Ony ${ }^{\circledR}$ (ev3 Neurovascular, Irvine, CA, USA), a mixture of ethylene-vinyl alcohol (EVOH), dimethyl sulfoxide (DMSO) and tantalum powder', was approved by the US Food and Drug Administration (FDA) in $2005^{10}$. Since then, several studies have reported the endovascular embolisation of brain vascular malformations using Onyx alone or in combination with detachable coils, and such procedures are associated with excellent results and low recanalisation rates ${ }^{11,12}$. Nevertheless, until now, no literature reports have described the transcatheter closure of CAF using Onyx embolisation.

In this article, we describe our preliminary experience of successful transarterial embolisation using coils and Onyx in CAF. To the best of our knowledge, this is the first series to evaluate the efficiency and safety of the transcatheter closure of CAF using the combination treatment of coils and Onyx.

\section{Editorial, see page 2102}

\section{Methods}

\section{PATIENT ENROLMENT}

Between September 2014 and September 2016, 12,673 consecutive patients were examined by coronary angiography at Changhai Hospital; of these, $41(0.32 \%)$ were diagnosed as having CAF. Large or moderate-sized CAFs in symptomatic patients were included in our study; small CAFs or those with additional complex cardiac disease requiring surgical treatment were excluded. According to the angiographic result, large CAFs were defined as $>2 \mathrm{x}$ distal reference vessel diameter; medium CAFs were defined as 1-2x distal reference vessel diameter; and small CAFs were defined as $<1 \mathrm{x}$ distal reference vessel diameter ${ }^{13}$.

A total of 26 patients were enrolled for attempted treatment with combined coils and Onyx. Patient demographics, fistula characteristics, and cardiac catheterisation data as well as followup data were analysed. The study protocol was approved by the Ethics Committee of Changhai Hospital, Second Military Medical University and was performed in accordance with the principles established in the Declaration of Helsinki. The choice of the combined therapy of coil and Onyx was discussed with all patients, and valid informed consents were obtained.

\section{EMBOLISATION AGENT}

Various sizes of Axium ${ }^{\mathrm{TM}}$ detachable coils or Axium ${ }^{\mathrm{TM}}$ Nylon detachable coils (both ev3 Neurovascular) were used in the procedure. These coils were used to form an initial framework into which Onyx was carefully injected through the microcatheter. Onyx (8\% EVOH and 92\% DMSO, and Onyx-34; or 6\% EVOH, 94\% DMSO, and Onyx-18) was chosen for the embolisation of CAF to achieve a higher occlusion rate. The microcatheter was pre-flushed with DMSO, and Onyx-34 or Onyx-18 was injected slowly under fluoroscopic control until total occlusion was achieved. To ensure adequate mixing and homogenous radiopacity of the Onyx mixture, the vials were placed in a shaker (VortexGenie; Scientific Industries, Inc., Bohemia, NY, USA) for at least 20 minutes before embolisation.

\section{ENDOVASCULAR PROCEDURE}

Briefly, the catheterisation procedure was performed under local anaesthesia through radial artery access in all cases. Heparin (100 IU/kg) was injected intravenously during the procedure. A 6 Fr guiding catheter (ENVOY ${ }^{\circledR}$; Cordis, Miami Lakes, FL, USA) was navigated into the target vessel where the fistula was located. Initially, an Echelon ${ }^{\mathrm{TM}} 10$ microcatheter (ev3 Neurovascular) was placed across the fistula ostium. Axium coils were then deployed into the arterial fistula through the microcatheter to form a scaffold structure. The number of coils used was determined based on the flow and size of the fistula. An Onyx-compatible Echelon 10 microcatheter was subsequently placed in the proximal segment of the coil mass, and Onyx-18 or Onyx-34 was then slowly injected to fill the interstices of the coil mesh until complete occlusion occurred. Both post-embolisation and follow-up coronary computed tomography angiography (coronary CTA) or angiography was performed to confirm complete obliteration of the fistula. All patients were prescribed maintenance antiplatelet therapy (aspirin plus clopidogrel for three months).

\section{CLINICAL AND ANGIOGRAPHIC FOLLOW-UP}

The follow-up protocol included assessments after one and six months and annually thereafter. All visits included a routine physical examination, electrocardiography, chest radiography, transthoracic echocardiography (TTE), and coronary CTA or coronary angiography (usually at nine to 12 months after embolisation). 


\section{STATISTICAL ANALYSIS}

All continuous variables are expressed as the mean \pm standard deviation (SD) or as medians with ranges as appropriate, and discrete variables are presented as frequencies and/or percentages. Continuous variables were compared using the unpaired Student's t-test and categorical variables by the chi-square test or the Fisher's exact test. All statistical analyses were performed using the SPSS software package, Version 19.0 (IBM Corp., Armonk, NY, USA).

\section{Results}

\section{BASELINE CHARACTERISTICS}

The clinical characteristics of 26 patients are summarised in Table 1. Of these patients, $17(65.4 \%)$ were women, and nine $(34.6 \%)$ were men; the mean age of the patients was $64.0 \pm 9.5$ years (range 44-78 years). CAFs were large in 10 patients and medium in 16 patients. Chest congestion was the most common symptom, presenting in $38.5 \%$ of the patients, followed by chest pain, presenting in $30.8 \%$ of patients. NYHA functional Class was II in nine patients, III in 13 patients and IV in four patients.

\section{ANGIOGRAPHIC RESULTS}

The sites of CAF origin and drainage are detailed in Figure 1. CAF most commonly originated from the left anterior descending artery (LAD), and fistulae drained most commonly into the pulmonary artery (PA). Procedural outcomes are summarised in Table 2. All 26 patients were successfully treated with the combination of the coils and Onyx, and complete closure was achieved in $23(88.5 \%$ ) patients (case 20, Figure 2, Moving image 1), and mild residual flow was achieved in three $(11.5 \%)$ patients (case 15, Figure 3, Moving image 2) as verified by immediate post-embolisation angiography. In case 2 , the patient had previously undergone transcatheter closure of CAF with coils alone. However, a significant residual shunt was found one year after the procedure: that failure was more likely due to the large size of the fistula. Therefore, the patient was enrolled in our study, then successfully treated with the combined therapy of three coils and $0.4 \mathrm{ml}$ Onyx-34 (Figure 4, Moving image 3).
Table 1. Clinical characteristics of all patients diagnosed with CAF ( $n=26)$.

\begin{tabular}{|c|c|c|}
\hline \multicolumn{2}{|l|}{ Women, n (\%) } & $17(65.4)$ \\
\hline \multicolumn{2}{|l|}{ Men, n (\%) } & $9(34.6)$ \\
\hline \multicolumn{2}{|l|}{ Age, yrs } & $64.0 \pm 9.5$ \\
\hline \multirow[t]{5}{*}{ Recorded symptoms, n (\%) } & Chest pain & $8(30.8)$ \\
\hline & Chest congestion & $10(38.5)$ \\
\hline & Palpitations & $5(19.2)$ \\
\hline & Dizziness & $2(7.7)$ \\
\hline & Syncope & $1(3.8)$ \\
\hline \multicolumn{2}{|c|}{ Murmur (continuous diastolic), n (\%) } & 7 (26.9) \\
\hline \multicolumn{2}{|l|}{ NYHA Class III/IV, n (\%) } & $17(53.8)$ \\
\hline
\end{tabular}

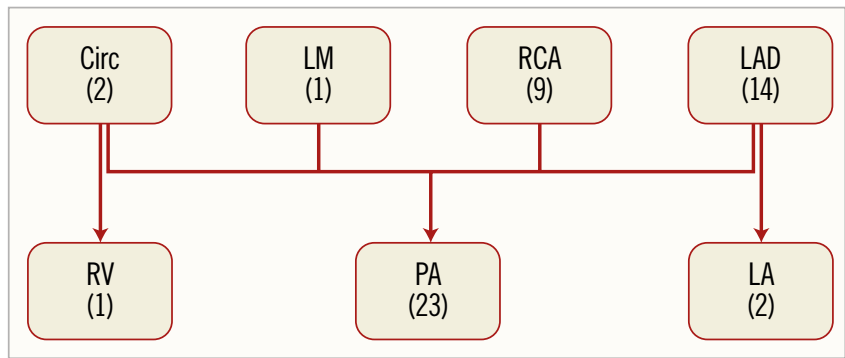

Figure 1. Coronary artery fistulae origin and drainage sites. Circ: circumflex artery; LA: left atrium; LAD: left anterior descending coronary artery; LM: left main; PA: pulmonary artery; $R C A$ : right coronary artery; $R V$ : right ventricle

Procedural details are summarised in Table 3. The mean number of coils used was 3.1, with a range of 2-6. An average of approximately $0.4 \mathrm{ml}$ of Onyx was injected, with a range between 0.2 and $0.6 \mathrm{ml}$. Onyx-18 was used in four (15.4\%) patients, and Onyx-34 was used in $22(84.6 \%)$ patients. During the procedure, no deaths, distal migration of Onyx or coils, embolic or haemorrhagic complications, catheter entrapment, fistula dissection, arrhythmia or pericardial tamponade occurred.

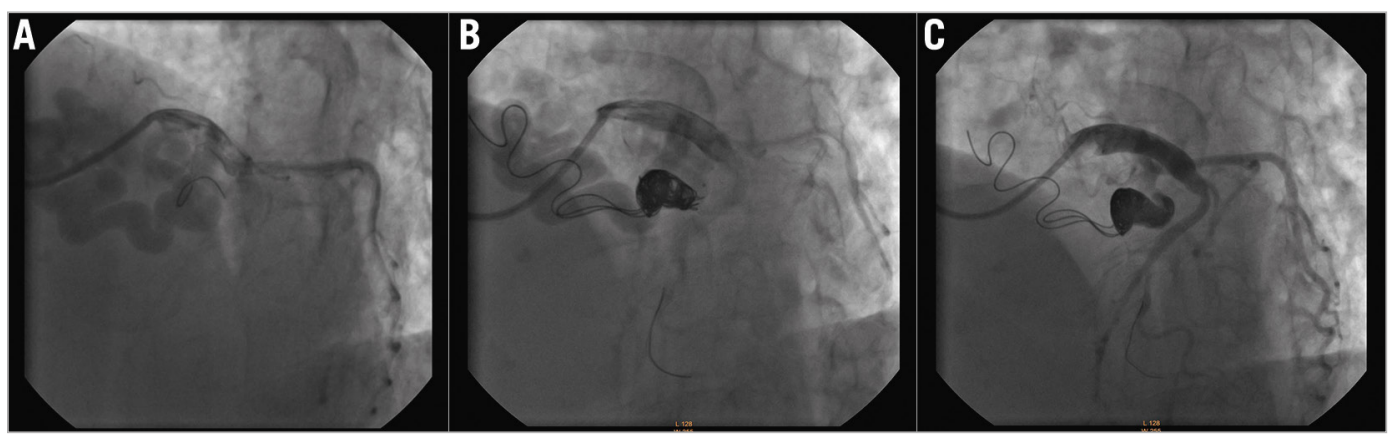

Figure 2. Coronary angiography in case 20 showing a giant fistula. A) A giant fistula originating from the LAD and draining into the pulmonary artery was identified in a 63-year-old woman. B) Three coils were initially deployed in the fistula, but significant residual flow remained. C) Residual flow disappeared completely after injecting $0.6 \mathrm{ml}$ of Onyx-34, as demonstrated by immediate post-embolisation angiography. 
Table 2. Procedural details and complications of patients.

\begin{tabular}{|c|c|c|c|c|c|c|c|c|c|}
\hline $\begin{array}{c}\text { Case } \\
\text { no. }\end{array}$ & $\begin{array}{l}\text { Age / } \\
\text { sex }\end{array}$ & $\begin{array}{l}\text { NYHA } \\
\text { class }\end{array}$ & Fistula site & Size of CAF & $\begin{array}{l}\text { No. of } \\
\text { coils used }\end{array}$ & $\begin{array}{c}\text { Onyx } \\
\text { volume (ml) }\end{array}$ & $\begin{array}{l}\text { Residual shunt } \\
\text { at discharge }\end{array}$ & $\begin{array}{l}\text { Recanalisation } \\
\text { on follow-up }\end{array}$ & $\begin{array}{l}\text { NYHA class } \\
\text { on follow-up }\end{array}$ \\
\hline 1 & $71 / F$ & III & LAD-to-PA & Medium & 3 & 0.2 & None & None & III \\
\hline 2 & $60 / \mathrm{M}$ & IV & LAD-to-PA & Large & 3 & 0.4 & None & None & II \\
\hline 3 & $57 / \mathrm{M}$ & III & LAD-to-PA & Medium & 3 & 0.3 & Mild & Trivial & II \\
\hline 4 & $73 / F$ & III & LAD-to-PA & Medium & 2 & 0.5 & None & Large & III \\
\hline 5 & $61 / F$ & II & LAD-to-PA & Medium & 2 & 0.3 & None & None & II \\
\hline 6 & $76 / F$ & III & LAD-to-PA & Large & 3 & 0.4 & None & None & III \\
\hline 7 & $44 / \mathrm{M}$ & II & LAD-to-LA & Medium & 2 & 0.2 & None & None & 1 \\
\hline 8 & $60 / \mathrm{M}$ & II & LCX-to-PA & Medium & 2 & 0.3 & None & None & II \\
\hline 9 & $67 / M$ & III & RCA-to-PA & Large & 5 & 0.25 & None & None & II \\
\hline 10 & $66 / F$ & II & RCA-to-PA & Medium & 3 & 0.4 & None & None & II \\
\hline 11 & $78 / F$ & III & LAD-to-LA & Medium & 2 & 0.5 & None & None & II \\
\hline 12 & $46 / \mathrm{M}$ & III & RCA-to-PA & Large & 4 & 0.6 & None & Trivial & III \\
\hline 13 & $52 / F$ & III & RCA-to-PA & Medium & 2 & 0.3 & None & None & 1 \\
\hline 14 & $75 / F$ & III & LAD-to-PA & Large & 4 & 0.5 & None & None & II \\
\hline 15 & $71 / F$ & III & LAD-to-PA & Large & 3 & 0.2 & Mild & None & III \\
\hline 16 & $68 / \mathrm{M}$ & IV & RCA-to-PA & Large & 6 & 0.2 & Mild & Trivial & III \\
\hline 17 & $62 / F$ & III & RCA-to-PA & Large & 5 & 0.4 & None & None & II \\
\hline 18 & $69 / F$ & II & RCA-to-PA & Medium & 2 & 0.3 & None & None & II \\
\hline 19 & $74 / F$ & II & LAD-to-PA & Medium & 2 & 0.3 & None & None & 1 \\
\hline 20 & $63 / F$ & III & LAD-to-PA & Large & 3 & 0.6 & None & None & II \\
\hline 21 & $76 / F$ & IV & LCX-to-RV & Large & 5 & 0.2 & None & None & III \\
\hline 22 & $59 / F$ & III & LAD-to-PA & Medium & 3 & 0.3 & None & None & 1 \\
\hline 23 & $63 / F$ & IV & RCA-to-PA & Medium & 2 & 0.5 & None & Trivial & II \\
\hline 24 & $61 / F$ & II & LCX-to-PA & Medium & 4 & 0.4 & None & None & II \\
\hline 25 & $46 / \mathrm{M}$ & II & RCA-to-PA & Medium & 3 & 0.3 & None & None & 1 \\
\hline 26 & $65 / M$ & II & LAD-to-PA & Medium & 2 & 0.6 & None & None & 1 \\
\hline
\end{tabular}

\section{LABORATORY DATA}

Creatinine (CRE) levels showed a slight increase at 24 hours after the procedure but recovered to preoperative levels at one month. There was no obvious change in blood urea nitrogen (BUN) levels before and after embolisation. Despite a significant increase in cardiac troponin I (cTnI) levels at 24 hours after operation, these remained in the normal range and decreased at one month, thereafter returning to the basal level at six months. The trends of changes in creatine kinase-MB (CK-MB) levels were the same as those for cTnI (Figure 5).

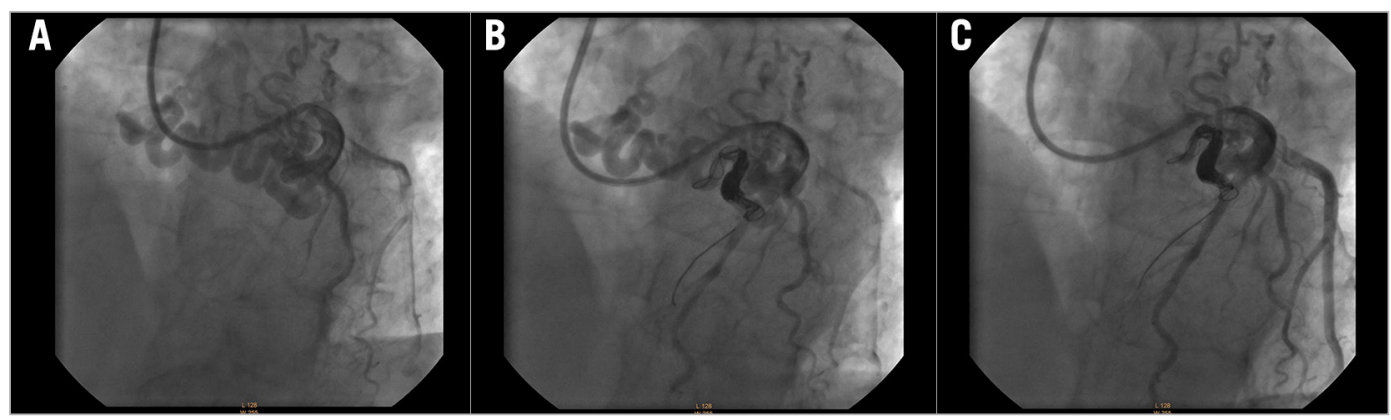

Figure 3. Coronary angiography in case 15 presenting a giant fistula. A) Coronary angiography showed that a fistula originated from the proximal segment of the LAD and drained into the pulmonary artery. B) Significant residual flow was observed after deploying 3 coils into the fistula. C) Coronary angiography revealed only a small amount of residual shunt after injection of $0.2 \mathrm{ml}$ of Onyx-34. 


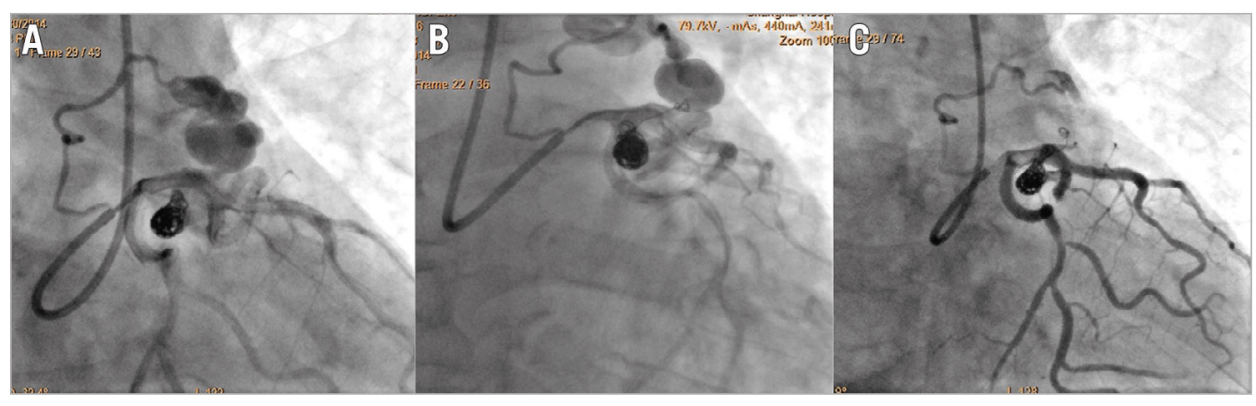

Figure 4. Coronary angiography in case 2 presenting with large recanalisation. A) Large recanalisation of CAF 12 months after embolisation using 3 coils was found in a 60-year-old man; B) immediate angiogram after the reocclusion of the CAF with 3 coils; C) coronary angiography confirmed complete occlusion after injection of $0.4 \mathrm{ml}$ of Onyx-34.

Table 3. Procedural data of all patients diagnosed with CAF $(n=26)$.

\begin{tabular}{|c|c|c|}
\hline \multirow[t]{2}{*}{ Angiographic sizing, n (\%) } & Large & $10(38.5)$ \\
\hline & Medium & $16(61.5)$ \\
\hline \multicolumn{2}{|l|}{ Procedure time, $\min$} & $52.6 \pm 11.6$ \\
\hline \multicolumn{2}{|l|}{ Fluoroscopy time, min } & $22.5 \pm 5.3$ \\
\hline \multicolumn{2}{|l|}{ Number of coils used } & $3.1 \pm 1.2$ \\
\hline \multicolumn{2}{|l|}{ Onyx volume, ml } & $0.4 \pm 0.1$ \\
\hline \multicolumn{2}{|l|}{ Hospital stay, days } & $4.8 \pm 1.2$ \\
\hline \multicolumn{2}{|l|}{ Follow-up period, months } & $12.3 \pm 3.4$ \\
\hline \multicolumn{2}{|c|}{ NYHA Class III/IV on follow-up, n (\%) } & $7(26.9)$ \\
\hline
\end{tabular}

Values are $n$, mean $\pm S D$, or $n(\%)$.
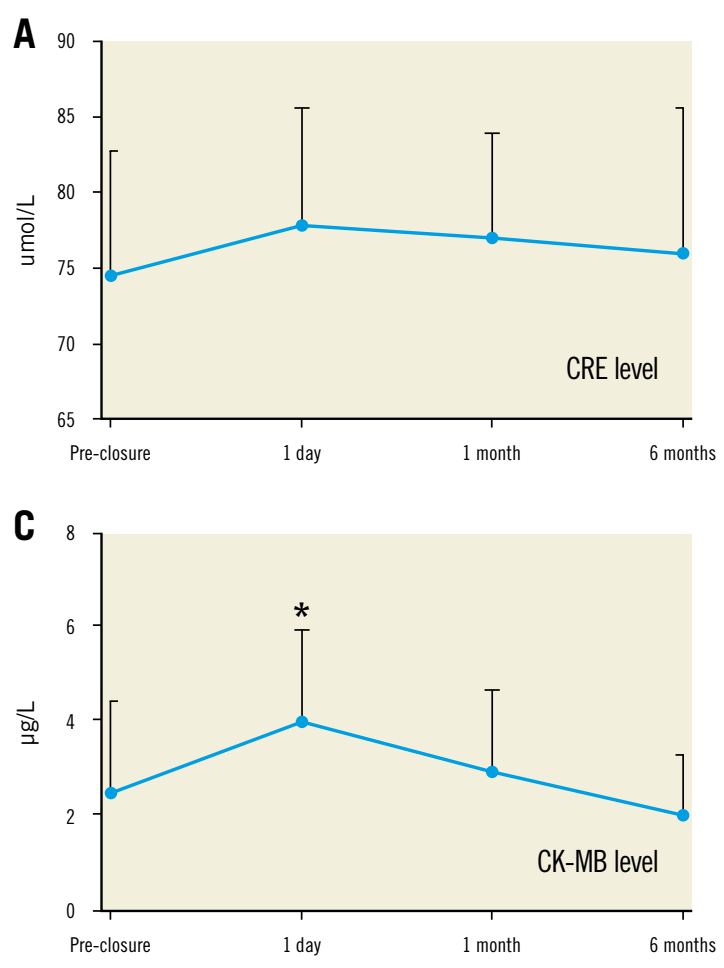

\section{CLINICAL FOLLOW-UP}

Follow-up data were available for all patients. The median follow-up period was 11.5 months (range, nine to 20 months) and included clinical symptom, blood test, ECG, TTE, chest X-ray, and coronary CTA or angiography monitoring. Improvement of symptoms was noted in 20 of the 26 patients (76.9\%), and symptoms were stable in six patients $(23.1 \%)$. Thirteen patients were in NYHA Class III and four patients were in NYHA Class IV at baseline. At the most recent follow-up, 10 patients were in NYHA Class II. Two patients were in NYHA Class IV at baseline and were classified in NYHA Class III at follow-up. The proportion of patients in NYHA Class III/IV was reduced from $53.8 \%$ at baseline to $26.9 \%$ at the time of last follow-up $(\mathrm{p}<0.05)$.
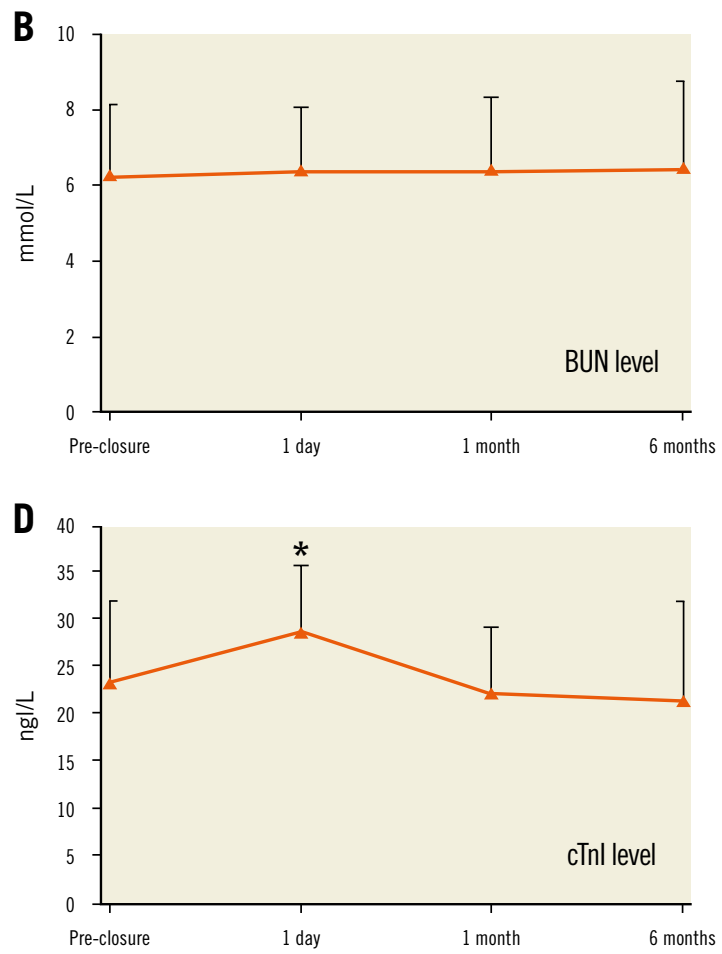

Figure 5. Laboratory data regarding kidney function and myocardial injury indices. A) Creatinine (CRE) levels. B) Blood urea nitrogen (BUN) levels. C) Creatine kinase-MB (CK-MB) levels. D) Serum cardiac troponin I (cTnI) levels. Data are presented as the mean $\pm S D($ range bars). ${ }^{*} p<0.05$ compared with the basal level. 
Angiographic follow-up was performed in 15 (57.7\%) patients, and follow-up CTA was obtained in $11(42.3 \%)$ patients after the initial procedure. A trivial-to-mild residual shunt immediately after the procedure disappeared in two patients and remained unchanged in one patient at follow-up. During the follow-up, recanalisation of the fistula was found in five (19.2\%) of the 26 patients; four $(15.4 \%)$ of these experienced trivial recanalisation, and the other patient (who was treated with two coils and $0.2 \mathrm{ml}$ Onyx-18) showed significant recanalisation at her 12-month follow-up angiography. The latter patient was then re-occluded with one additional coil and $0.3 \mathrm{ml}$ Onyx-34, and no recanalisation was verified by CTA at the six-month follow-up. No other procedurerelated complications, such as distal migration of Onyx or coils, strokes, fistula dissection, or infective endocarditis, were observed during the follow-up period.

\section{Discussion}

Although it remains the most commonly used device for endovascular occlusion of $\mathrm{CAF}^{14}$, the detachable coil has the disadvantages of a low success rate and high recanalisation rate ${ }^{3,7}$. Especially for large, tortuous or multiple fistula ostia, transcatheter coil embolisation may be technically difficult, with inaccurate placement potentially leading to inadequate occlusion ${ }^{15}$. Consequently, multiple coils may be required to obtain satisfactory fistula occlusion ${ }^{1,16}$, but the procedure is lengthy and expensive ${ }^{17}$. Currently, Onyx is usually used in combination with coils for the embolisation of brain vascular malformations ${ }^{18-21}$. Thus far, no data have been published on the combined use of coils and Onyx for the treatment of CAFs.

In our series, we first report the short-term findings of transarterial coiling and subsequent Onyx embolisation in 26 patients with large CAFs. Compared with coil embolisation alone, deploying coils before Onyx injection can slow the blood flow of the fistula and produce a "strong armoured concrete" structure ${ }^{22}$, which may embolise the fistula more reliably. Indeed, in the present study, successful occlusion occurred immediately in all patients with no residual flow in $88.5 \%$ cases and with trivial flow in $11.5 \%$ cases. The immediate closure success rate in our series was better than previous reports of transcatheter closure studies involving coils alone ${ }^{16,23}$

Nevertheless, despite the high occlusion rate, recanalisation remains the most serious complication when using Onyx embolisation ${ }^{13}$. Ambekar et al showed that the risk of fistula recanalisation was high in the first year after Onyx embolisation ${ }^{24}$. In our series, median 11.5-month follow-up imaging indicated that, when using transcatheter closure with a combined treatment of coils and Onyx, only $19.2 \%$ of patients experienced recanalisation; this rate is significantly lower than that reported by Jama et al for their series of 29 patients $^{14}$, who underwent transcatheter closure using coils or other occlusion devices alone (44.4\% recanalisation rate). Of note, trivial recanalisation was detected in two of 22 patients $(9.1 \%)$ treated with Onyx-34; however, trivial to significant recanalisation was found in three of four patients $(75 \%)$ who were treated with Onyx-18. The patient with significant recanalisation was re-occluded completely using Onyx-34, indicating that Onyx34 might be more suitable than Onyx-18 for occluding CAFs, in particular for larger fistulae.

Furthermore, the use of Onyx in association with coils greatly reduced the number of coils that needed to be used, thereby decreasing medical expense and fluoroscopy time ${ }^{25}$. The number of coils required to achieve satisfactory occlusion has been reported to be as high as $25^{17}$. In comparison, on average, only 3.1 coils were needed when used in combination with Onyx to achieve stable occlusion in the present study. The volume of Onyx used in our series was much less (average, $0.4 \mathrm{ml}$ ) than that needed for the transarterial embolisation of traumatic carotid cavernous fistulae using Onyx alone (average, $3.94 \mathrm{ml})^{10}$. Of note, based on the financial data from our institution (for example, the total medical cost of two coils plus Onyx is US\$5,969 versus US\$9,696 for four coils), we hypothesised that the combined treatment of Onyx and coils might be cheaper than procedures with coils alone.

Several technical issues could account for the high procedural success rate and fewer complications. First, the avoidance of Onyx reflux into normal vessels is essential for preventing severe ischaemic events. It is therefore important to achieve tight packing with coils before Onyx injection and to use an injection site distant from the main functional vessels of the coronary artery. Usually, the microcatheter is placed in the narrowest part of the distal fistula; if there is no obvious stenosis of the fistula, the microcatheter will be placed at least $2-3 \mathrm{~cm}$ from the fistula opening. Second, Onyx has non-adhesive properties but still carries the risk of catheter entrapment ${ }^{26,27}$. In the present study, we placed the tip of the microcatheter over the proximal portion of the coil mass, which may lead to ease of catheter extraction and allow the Onyx to penetrate within the coil interstices. Indeed, no occurrence of catheter entrapment or difficult catheter removal was reported in our study. Third, the injection of Onyx under radiographic control is critical to achieving total occlusion. During the procedure, a small amount (approximate 0.1-0.2 ml) of Onyx was initially injected, and the interventionalist then waited three to five minutes. A little more Onyx was then injected if a significant residual shunt remained upon angiographic observation. This process "injection-angiography-injection" was repeated until angiography demonstrated satisfactory occlusion of the fistula.

Additionally, Onyx is dissolved in an organic solvent DMSO, with the potential for cardiovascular toxicity or renal injury. However, the laboratory indices did not change significantly after coiling and Onyx embolisation, possibly due to the small amount of Onyx used in this series. Moreover, based on our experience, to reduce thrombotic events resulting from endothelial injury caused by microcatheterisation, all cases received short-term dual antiplatelet treatment. Nevertheless, considering that antithrombotic therapy may inhibit thrombus generation and thus decrease the complete occlusion rate, the application of antiplatelet and/or anticoagulation treatment after coil placement and Onyx injection remains controversial. 


\section{Limitations}

Our study has several limitations. This study was a retrospective, single-institution study involving a small population with a short follow-up; thus, the actual efficacy of the endovascular coiling and Onyx embolisation technique might not have been ascertained. Therefore, further studies with larger sample sizes and long-term follow-up are required to confirm our findings. Angiographic follow-up was available for only $57.7 \%$ of patients, and coronary CTA was performed at follow-up in the remaining patients. Increasing evidence shows that coronary CTA can be delineated non-invasively and with high accuracy for diagnosing $\mathrm{CAF}^{28}$. However, the sensitivity of computed tomography versus angiography for identifying small recanalisation events remains controversial.

\section{Conclusions}

Our results indicated that coil placement in combination with Onyx embolisation yielded a high rate of procedural success with few complications. However, this report describes our preliminary experience with a limited number of patients and a short followup period. Hence, further investigations are needed to clarify the efficacy and safety of procedures using coils and Onyx.

\section{Impact on daily practice}

Coronary artery fistula (CAF), the most common coronary artery malformation, has potential complications and requires immediate treatment. Transcatheter coil closure has been the mainstay of therapy for CAF and exhibits a relatively low complication rate. Unfortunately, it also carries the disadvantage of a high rate of recanalisation, and its use is limited in patients with large or twisted fistulae. Here, we reported transcatheter embolisation using a combination of coils and Onyx. This method was found to be an attractive and successful alternative for selected patients with CAF.

\section{Conflict of interest statement}

The authors have no conflicts of interest to declare.

\section{References}

1. Thomson L, Webster M, Wilson N. Transcatheter closure of a large coronary artery fistula with the Amplatzer duct occluder. Catheter Cardiovasc Interv. 1999;48:188-90.

2. Liang CD, Ko SF. Midterm outcome of percutaneous transcatheter coil occlusion of coronary artery fistula. Pediatr Cardiol. 2006;27:557-63.

3. Collins N, Mehta R, Benson L, Horlick E. Percutaneous coronary artery fistula closure in adults: technical and procedural aspects. Catheter Cardiovasc Interv. 2007;69:872-80.

4. Warnes CA, Williams RG, Bashore TM, Child JS, Connolly HM, Dearani JA, Del Nido P, Fasules JW, Graham TP Jr, Hijazi ZM, Hunt SA, King ME, Landzberg MJ, Miner PD,
Radford MJ, Walsh EP, Webb GD. ACC/AHA 2008 Guidelines for the Management of Adults with Congenital Heart Disease: Executive Summary: a report of the American College of Cardiology/American Heart Association Task Force on Practice Guidelines (writing committee to develop guidelines for the management of adults with congenital heart disease). Circulation. 2008;118:2395-451.

5. Mavroudis C, Backer CL, Rocchini AP, Muster AJ, Gevitz M. Coronary artery fistulas in infants and children: a surgical review and discussion of coil embolization. Ann Thorac Surg. 1997;63: 1235-42.

6. Wiegand G, Sieverding L, Kaulitz R, Hofbeck M. Transarterial and transvenous approach for transcatheter closure of a large coronary artery fistula with the Amplatzer vascular plug. Pediatr Cardiol. 2009;30:172-5.

7. Petrie MC, Peels JO, Jessurun G. The role of covered stents: more than an occasional cameo? Catheter Cardiovasc Interv. 2006;68:216.

8. Sadiq M, Wilkinson JL, Qureshi SA. Successful occlusion of a coronary arteriovenous fistula using an Amplatzer duct occluder. Cardiol Young. 2001;11:84-7.

9. Yu Y, Huang Q, Xu Y, Hong B, Zhao W, Deng B, Zhang Y, Liu J. Use of onyx for transarterial balloon-assisted embolization of traumatic carotid cavernous fistulas: a report of 23 cases. AJNR Am J Neuroradiol. 2012;33:1305-9.

10. Ayad M, Eskioglu E, Mericle RA. Onyx: a unique neuroembolic agent. Expert Rev Med Devices. 2006;3:705-15.

11. Ramalingaiah AH, Prasad C, Sabharwal PS, Saini J, Pandey P. Transarterial treatment of direct carotico-cavernous fistulas with coils and Onyx. Neuroradiology. 2013;55:1213-20.

12. Fang YB, Li Q, Yang PF, Zhang Q, Wu YN, Feng ZZ, Huang QH, Xu Y, Liu JM. Application of endovascular coiling and subsequent Onyx 34 embolization in anterior communicating artery aneurysms with adjacent hematoma. Clin Neurol Neurosurg. 2014;123:40-4.

13. Reddy G, Davies JE, Holmes DR, Schaff HV, Singh SP, Alli OO. Coronary artery fistulae. Circ Cardiovasc Interv. 2015;8:e003062.

14. Jama A, Barsoum M, Bjarnason H, Holmes DR Jr, Rihal CS. Percutaneous closure of congenital coronary artery fistulae: results and angiographic follow-up. JACC Cardiovasc Interv. 2011;4: 814-21.

15. Alekyan BG, Podzolkov VP, Cárdenas CE. Transcatheter coil embolization of coronary artery fistula. Asian Cardiovasc Thorac Ann. 2002;10:47-52.

16. Lacombe P, Rocha P, Marchand X, Mulot R, Rigaud M, Jondeau G, Weber JM, Kahn JC. High flow coronary fistula closure by percutaneous coil packing. Cathet Cardiovasc Diagn. 1993;28: 342-6.

17. Chalouhi N, Starke RM, Tjoumakaris SI, Jabbour PM, Gonzalez LF, Hasan D, Rosenwasser RH, Dumont AS. Carotid and vertebral artery sacrifice with a combination of Onyx and coils: technical note and case series. Neuroradiology. 2013;55: 993-8. 
18. Katsaridis V, Papagiannaki C, Aimar E. Curative embolization of cerebral arteriovenous malformations (AVMs) with Onyx in 101 patients. Neuroradiology. 2008;50:589-97.

19. Dabus G, Pizzolato R, Lin E, Kreusch A, Linfante I. Endovascular treatment for traumatic scalp arteriovenous fistulas: results with Onyx embolization. J Neurointerv Surg. 2014;6:405-8.

20. Taki W, Yonekawa Y, Iwata H, Uno A, Yamashita K, Amemiya H. A new liquid material for embolization of arteriovenous malformations. Am J Neuroradiol. 1990;11:163-8.

21. Baccin CE, Campos CM, Abicalaf R, Kanashiro LH, Bolcato MR, Lima SS, Piske RL. Traumatic carotid-cavernous fistula: endovascular treatment with onyx and coils. Interv Neuroradiol. 2005;11:363-7.

22. Zhang X, Guo W, Shen R, Sun J, Yin J, Chen X, Gao L, Chen Z, Zhang Q. Combined use of Onyx and coils for transarterial balloon-assisted embolization of traumatic carotid-cavernous fistulas: a report of 16 cases with 17 fistulas. J Neurointerv Surg. 2016 Jan 14. [Epub ahead of print].

23. Munawar M, Siswanto BB, Harimurti GM, Nguyen TN. Transcatheter closure of coronary artery fistula using Guglielmi detachable coil. J Geriatr Cardiol. 2012;9:11-6.

24. Ambekar S, Gaynor BG, Peterson EC, Elhammady MS. Longterm angiographic results of endovascularly "cured" intracranial dural arteriovenous fistulas. J Neurosurg. 2016;124:1123-7.

25. Hassan T, Rashad S, Aziz W, Sultan A, Ibrahim T. Endovascular Modalities for the Treatment of Cavernous Sinus
Arteriovenous Fistulas: a Single-Center Experience. J Stroke Cerebrovasc Dis. 2015;24:2824-38.

26. Vu PD, Grigorian AA. Microcatheter entrapment retrieval from Onyx embolization in brain arteriovenous malformations: a technical note. Interv Neuroradiol. 2015;21:620-3.

27. Qureshi AI, Mian N, Siddiqi H, Qureshi MH, Malik AM, Rauf Afzal M, Khan AA, Suri MF. Occurrence and Management Strategies for Catheter Entrapment with Onyx Liquid Embolization. J Vasc Interv Neurol. 2015;8:37-41.

28. Early SA, Meany TB, Fenlon HM, Hurley J. Coronary artery fistula; coronary computed topography--the diagnostic modality of choice. J Cardiothorac Surg. 2008;3:41.

\section{Supplementary data}

Moving image 1. Angiography showing a large coronary artery fistula that was completely closed using a combination of coils and Onyx.

Moving image 2. Using coils and Onyx, a large coronary artery fistula was successfully closed; residual flow was mild, as verified by immediate post-embolisation angiography.

Moving image 3. Re-embolisation was performed; angiography showed no residual flow.

The supplementary data are published online at:

http://www.pcronline.com/

eurointervention/133rd_issue/353 